While the concurrent administration of gamma-globulin and measles vaccine would be suitable for immunization on a limited scale in England, this method would be less suitable for extensive use than an effective vaccine which produced a low reaction rate when given alone. However, a dose as small as $0.004 \mathrm{ml} . / \mathrm{lb}$. $(0.0088 \mathrm{ml} . / \mathrm{kg}$.) proved effective in one of our trials. The difficulty and expense of providing it might be counteracted by a reduction of subsequent calls on gammaglobulin as a prophylactic to susceptible contacts. Neither vaccine 14 nor vaccine 16 was found to be suitable when given without gamma-globulin. Both produced pronounced reactions when given alone, and in this respect resembled vaccine $4 \mathrm{~A}$, which had been used alone in a previous trial (Aldous et al., 1961).

In contrast to the experience with vaccines 14 and 16 , vaccine 20 produced only very mild reactions. These findings in English children confirm the more extensive observations at Ibadan University, Nigeria (Hendrickse et al., 1964).

The reason for the lower reaction rate of vaccine 20 is not quite clear. Two other vaccine strains have also been reported with low reaction rates (W.H.O., 1963). All have been passaged a large number of times in chick-embryo-tissue cultures. On the other hand, vaccine 14 was still causing marked reactions after 65 further passages in tissue culture beyond Enders's vaccine A.

The low reaction rate and satisfactory antibody response after vaccine 20 suggest that this or other vaccines attenuated to a similar degree would be suitable for use in Britain on an extensive scale.

\section{Summary}

The vaccination reaction and antibody response to Edmonston $B$ and three further attenuated measles vaccines derived from Enders's strains have been examined in a total of 122 English infants.

Enders's original vaccine alone or with further attenuation by 20 or 24 extra passages in chick-embryo tissue produced reactions which were modified by gamma-globulin in as small a dosage as $0.004 \mathrm{ml} . / \mathrm{lb}$. ( $0.0088 \mathrm{ml} . / \mathrm{kg}$.) body weight.

Vaccine 20, a further-attenuated vaccine given without gamma-globulin, caused only mild reactions but a satisfactory antibody response. Of the vaccines so far tested it appears to hold most promise of proving acceptable for routine use.

We thank Dr. R. C. Mac Keith, Miss M. Theisen, and the staff of Salomons' Centre, Guy's Hospital ; and Dr. R. E. BonhamCarter, Sister Curtis, and the staff of the Child Welfare Department, University College Hospital.

\section{REFERENCES}

Aldous, I. R., Kirman, B. H., Butler, N., Goffe, A. P., Laurence, G. D. and Pollock, T. M. (1961). Bril. med. f., 2, 1250.

Enders, J. F., Katz, S. L., Milovanović, M. V., and Holloway, A. (1960). New Engl. F. Med., 263, 153.

Goffe, A. P., and Laurence, G. D. (1961). Brit. med. F., 2, 1244.

Hendrickse, R. G., Montefiore, D., Sherman, P. M., and van der Wall, H. M. (1964). Ibid., 1, 470.

Katz, S. L. (1964). Seminar on Epidemiology and Prevention of Measles and Rubella, International Children's Centre, Paris.

Kress, S., Schluederberg, A. E., Hornick, R. B., Morse, L. J., Cole, J. L., Slater, E. A., and McCrumb, F. R. (1961). Amer. f.' Dis. Child., 101, 701 .

Krugman, S., Giles, J. P., Jacobs, A. M., and Friedman, H. (1962) Amer. F. publ. Hith, 52, Suppl. p. 16.

Miller, D. L. (1964). Brit. med. f., 2, 75.

Stokes, J., Hilleman, M. R., Weibel, R. E., Buynak, E. B., and Halenda, R. (1962). New Engl.' \%. Med., 267, 222.

W.H.O. Scientific Group (1963). Wld Hlth Org. techn. Rep. Ser. No. 263. as suffering from poliomyelitis. Within the next four weeks numerous other patients were admitted to hospital for investigation, and of these 31 were accepted as suffering from poliomyelitis. The weekly incidence of new cases by dates of sickening is shown in Table I. Virological investigation showed that the outbreak was due to poliovirus type 1.

TABLE I.-Weekly Incidence of New Cases of Poliomyelitis by Dates \begin{tabular}{l|c|c|c|c|c|c|c}
\hline Week ending: & May 26 26 & June 2 & June 9 & June 16 & June 23 & June 30 & July 7 \\
No. of cases: & 4 & 7 & 7 & 6 & 2 & 2
\end{tabular}

Early in the outbreak it became apparent that the main incidence was in one peripheral housing scheme in the northeast of the city. Of the 40 cases finally accepted 29 came from this scheme or its immediate vicinity, while many of the others either had direct contact with this area or indirect contact through visiting relatives. Twenty cases actually occurred in close proximity to each other, and seven of these patients 
lived in the same street. Two cases were reported from each of five households, while in the sixth instance a nephew probably infected his uncle. A high degree of association was found in the infected children themselves, either through school or the local day nursery, and in relatives through visiting in adjacent households. The relatives of two children who sickened during the first week of the outbreak had visited an area of Glasgow from which poliomyelitis had been reported earlier in the year. Common sources of food supplies were noted, but this was not surprising in such a concentrated housing area ; one feature, however, was that a local ice-cream vendor, from whose van almost three-quarters of the cases had received their supplies, had a child affected in the latter part of the outbreak.

\section{Clinical Features}

The type of illness in the 40 patients is shown in Table II. In this outbreak males outnumbered females 24 to 16 . Most of the patients were in the younger age-groups, only five being over the age of 6 years; the youngest was 8 months and the oldest was a man of 38 , who was the only patient in the series to die.

TABLE II.-Age, Sex, and Type of Illness in the 40 Cases

\begin{tabular}{|c|c|c|c|c|c|c|c|c|c|c|c|}
\hline \multirow{4}{*}{ Age in Years } & & \multicolumn{10}{|c|}{ No. of Patients Whose Disease was } \\
\hline & & \multirow{2}{*}{\multicolumn{2}{|c|}{$\begin{array}{c}\text { Non- } \\
\text { paralytic }\end{array}$}} & \multicolumn{8}{|c|}{ Paralytic } \\
\hline & & & & \multicolumn{2}{|c|}{ Spinal } & \multicolumn{2}{|c|}{ Bulbar } & \multicolumn{2}{|c|}{$\begin{array}{l}\text { Bulbo- } \\
\text { spinal }\end{array}$} & \multicolumn{2}{|c|}{$\begin{array}{c}\text { Encephalo } \\
\text { spinal } \\
\end{array}$} \\
\hline & & $M$ & $F$ & $M$ & $\mathrm{~F}$ & $M$ & $\mathrm{~F}$ & $M$ & $\mathbf{F}$ & $\mathbf{M}$ & $\mathbf{F}$ \\
\hline 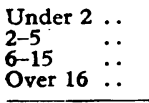 & $\begin{array}{l}\because \\
\because \\
\therefore\end{array}$ & $\begin{array}{l}\frac{1}{7} \\
\frac{1}{1}\end{array}$ & $\begin{array}{l}\overline{4} \\
\overline{-}\end{array}$ & $\begin{array}{l}3 \\
7 \\
- \\
- \\
\end{array}$ & $\begin{array}{r}3 \\
4 \\
1 \\
-\end{array}$ & $\begin{array}{l}\overline{2} \\
\overline{-}\end{array}$ & $\begin{array}{l}\overline{2} \\
2 \\
-\end{array}$ & $\begin{array}{l}\frac{1}{1} \\
\frac{1}{1 *}\end{array}$ & $\begin{array}{l}\bar{z} \\
\bar{z}\end{array}$ & $\overline{\overline{1}}$ & $\begin{array}{l}\bar{z} \\
\bar{z}\end{array}$ \\
\hline Over $16 \quad$. & & 9 & 4 & 10 & 8 & 2 & 4 & 2 & - & 1 & - \\
\hline Total & .. & \multicolumn{2}{|c|}{13} & \multicolumn{2}{|c|}{18} & \multicolumn{2}{|c|}{6} & \multicolumn{2}{|c|}{2} & \multicolumn{2}{|c|}{1} \\
\hline
\end{tabular}

The illness was non-paralytic in 13 patients, all of whom presented as cases of aseptic meningitis except one who had respiratory symptomatology only. Cranial-nerve involvement was present in six patients: one had palatal paralysis, three had facial paralysis, one had facial and pharyngeal paralysis, and in one the left external rectus ocular muscle was affected; all of these paralyses had either cleared completely or were minimal within a month of onset except in one patient in whom facial palsy persisted. Spinal-cord involvement was present in 18 patients, the severity in nine being such as to require transfer to an orthopaedic hospital after one month.

Cranial-nerve and spinal-cord involvement occurred in two patients. The first was a boy with paralysis of facial, intercostal, and diaphragmatic muscles and paralysis of both legs; he recovered completely within two months. The second was a man aged 38 who had quadriplegia and pharyngeal and respiratory paralyses, and who died within 24 hours of admission to hospital despite tracheostomy and positive-pressure ventilation.

One child presented with encephalitic symptoms-convulsions, tremors, and slight ataxia ; he appeared to make a good recovery, but about one month later was noticed to be limping and was found to have lower-motor-neurone paralysis affecting one leg; this disappeared completely within a further two months.

\section{Clinical Illness Related to Previous Immunization}

The type and severity of the clinical illness relative to the history of previous immunization with poliovaccine are set out in Table III. The assessment of the severity of paralysis was carried out by Mr. J. Hutchison, orthopaedic surgeon, who had been involved in the orthopaedic care of the patients but who had no knowledge of their immunization. The criteria considered were the extent, degree, and duration of paralysis, and the assessment was carried out about a year after the outbreak.

It will be seen that while there was only one severely paralysed case in those receiving two or more doses of inactivated vaccine, there were four severely paralysed and three moderately paralysed cases among those who had not received this vaccine (two patients had received one dose of live vaccine).

TABLE III.-Clinical Illness Related to Previous Immunization

\begin{tabular}{c|c|c|c|c|c}
\hline \multicolumn{2}{c|}{ Immunization History } & \multicolumn{3}{|c}{ No. of Patients with Illness of Type } \\
\hline $\begin{array}{c}\text { Inactivated } \\
\text { Vaccine } \\
\text { No. of Doses }\end{array}$ & $\begin{array}{c}\text { Live } \\
\text { Vaccine } \\
\text { No. of Doses }\end{array}$ & Non-paralytic & \multicolumn{2}{|c|}{ Paralytic } \\
\hline 3 & 2 & 1 & 0 & 0 & 0 \\
3 & 1 & 1 & 0 & 0 & 0 \\
3 & 0 & 2 & 4 & 0 & 1 \\
2 & 0 & 2 & 0 & 0 \\
\hline 1 & 0 & 1 & 1 & 0 & 0 \\
0 & 1 & 5 & 5 & 0 & 2 \\
0 & 0 & 1 & 5 & 3 & 2 \\
\hline
\end{tabular}

\section{Virological Investigation}

A specimen of faeces, collected usually on the day of admission to hospital, a specimen of cerebrospinal fluid, and paired sera were submitted to the laboratory for virological investigation.

\section{Methods}

Primary human amnion stationary monolayer cultures were prepared by the technique of Duncan and Bell (1961) and secondary monolayer monkey-kidney cultures by the technique of Mair and Tobin (1960). The monkey-kidney cultures were supplied by the Wellcome Research Laboratories.

Faecal extracts (10\% suspensions) were made in Dulbecco phosphate-buffered saline containing penicillin (250 units $/ \mathrm{ml}$.), streptomycin $(250 \mu \mathrm{g} . / \mathrm{ml}$.$) , and nystatin (62.5 units / \mathrm{ml}$.). After centrifugation at 3,000 r.p.m. for 30 minutes the supernatant was stored at $-40^{\circ} \mathrm{C}$.

Two tubes of human amnion and monkey-kidney tissue culture were inoculated with faecal extract in the following way. The maintenance medium was removed from the tubes and $0.2 \mathrm{ml}$. of faecal extract was added to each. After incubation for one hour at $37^{\circ} \mathrm{C}$., fresh maintenance medium was added and the tubes were incubated at $37^{\circ} \mathrm{C}$. and examined daily for a cytopathic effect (C.P.E.) ; when a C.P.E. appeared the tube was frozen at $-40^{\circ} \mathrm{C}$. and the fluid, after thawing and being centrifuged at 3,000 r.p.m. for 30 minutes, was diluted suitably and tested against trivalent poliovirus antiserum and poliovirus 1, 2, 3 monospecific sera (Burroughs Wellcome) in neutralization tests ; the tests were read after three days' incubation at $37^{\circ} \mathrm{C}$. If no isolation was obtained the faecal extract was inoculated into monkey-kidney cultures to which had been added, 24 hours previously, maintenance medium containing added magnesium ions (Wallis and Melnick, 1962). Cerebrospinal fluid was inoculated into tissue cultures in the same manner as faecal extracts. For serum neutralization tests the method of Shand (1961) was adopted, using 100 TCID $_{50}$ of virus and doubling dilutions of the patient's serum from 1 in 8 upwards; readings were made at three- and seven-day intervals.

Complement fixation tests for antibodies to mumps $\mathrm{S}$ and $\mathrm{V}$ antigens were carried out, using a standard volume technique with 2 M.H.D. complement and overnight fixation at $4^{\circ} \mathrm{C}$. The antigens were kindly supplied by the Standards Laboratory for Serological Reagents, London. 


\section{Results}

Specimens of faeces and cerebrospinal fluid were obtained from 36 cases. No poliovirus was isolated from the cerebrospinal fluids. Poliovirus type 1 was isolated from $32(88 \%)$ of the 36 faecal specimens. Most of the strains (29) produced a C.P.E. on primary isolation in both primary human amnion and monkey-kidney tissue cultures. The three strains that failed to grow on these cultures were isolated on monkeykidney tissue culture with added $\mathrm{Mg}$ ions, and they passed without difficulty to both the human amnion and monkeykidney tissue cultures without added $\mathrm{Mg}$ ions.

The isolation rate correlated with the number of cases is shown in Table IV.

When isolations are correlated with the vaccination state and clinical condition of the patients, as shown in Table IV, it will be seen that of the four patients with negative stool cultures three were paralytic cases and one was non-paralytic; the vaccination state and the presence of neutralizing antibodies in these four patients are shown in Table V.

TABLE IV.-Isolation of Poliovirus Type 1 Correlated with Vaccination State and Clinical Condition of Patients

\begin{tabular}{c|c|c|c|c}
\hline \multicolumn{2}{c|}{$\begin{array}{c}\text { No. of Doses of Vaccine } \\
\text { Received by Patient }\end{array}$} & \multicolumn{2}{c|}{$\begin{array}{c}\text { No. of Patients Yielding } \\
\text { Poliovirus with } \\
\text { Paralytic Disease }\end{array}$} & $\begin{array}{c}\text { No. of Patients with } \\
\text { Non-paralytic } \\
\text { Disease }\end{array}$ \\
Inactivated & Live & Bulbar & Spinal & \\
\hline 3 & 2 & 0 & 0 & $1 / 1$ \\
3 & 1 & 0 & 0 & $1 / 1$ \\
3 & 0 & $1 / 3$ & $1 / 2^{*}$ & $1 / 2$ \\
2 & 0 & $2 / 2$ & $1 / 2^{*}$ & $2 / 2$ \\
1 & 0 & 0 & $1 / 1$ & $1 / 1$ \\
0 & 1 & $1 / 1$ & $5 / 6$ & $5 / 5$ \\
0 & 0 & $1 / 2^{*}$ & $7 / 8^{*}$ & $1 / 1$ \\
\hline
\end{tabular}

Numerator denotes number of isolations. Denominator denotes number of cases. * No specimen obtained.

Table V.-Clinical Details, Vaccination State, and Production of Poliovirus Type 1 Neutralizing Antibodies in Cases in Which No Isolation was Made From Faeces

\begin{tabular}{|c|c|c|c|c|c|c|c|}
\hline \multirow[b]{2}{*}{ Sex } & \multirow[b]{2}{*}{ Age } & \multicolumn{2}{|c|}{ Vaccine Doses } & \multicolumn{2}{|c|}{ Paralysis } & \multirow{2}{*}{$\begin{array}{l}\text { No } \\
\text { para- } \\
\text { lysis }\end{array}$} & \multirow{2}{*}{$\begin{array}{l}\text { Serum } \\
\text { Neutralization } \\
\text { to Poliovirus 1 }\end{array}$} \\
\hline & & $\begin{array}{l}\text { Inacti- } \\
\text { vated }\end{array}$ & Live & Bulbar & Spinal & & \\
\hline $\begin{array}{l}\mathrm{F} \\
\mathrm{F}\end{array}$ & $\begin{array}{l}4 \text { years } \\
10 \text {," }\end{array}$ & $\begin{array}{l}3 \\
3\end{array}$ & $\begin{array}{l}0 \\
0\end{array}$ & $\bar{t}$ & $\overline{-}$ & \pm & $\begin{array}{l}\text { No specimens } \\
\text { Fourfold rise }\end{array}$ \\
\hline$\underset{\mathbf{M}}{\mathbf{F}}$ & 10 months & $\begin{array}{l}3 \\
0\end{array}$ & $\begin{array}{l}0 \\
1 *\end{array}$ & \pm & $\bar{t}$ & $\overline{-}$ & " $\quad$ " \\
\hline
\end{tabular}

* This child had one dose of live vaccine 14 days before admission to hospital.

There were two complicating factors in the virological investigations. Firstly, as trivalent live vaccine had been used it was necessary to carry out intratypic differentiation on the type 1 isolates in patients who had received the live vaccine. Secondly, there was an outbreak of mumps in the city at the same time as the outbreak of poliomyelitis.

With regard to the first complication, 11 strains were sent to Dr. Eleanor J. Bell (Glasgow) for intratypic serodifferentiation, carried out by the method described by Goffe and Bell (1963). Ten of the strains were shown to behave like wild poliovirus type 1 , and the other was a mixture of two viruses not yet fully typed. The intervals between the giving of live vaccine and the onset of illness in the 10 patients are shown

TABLE VI.-Interval Between Giving of Live Vaccine and Onset of Illness in 10 Patients from whom Poliovirus was Isolated

\begin{tabular}{|c|c|c|c|c|c|}
\hline \multirow{2}{*}{ Sex } & \multirow{2}{*}{$\begin{array}{l}\text { Age in } \\
\text { Years }\end{array}$} & \multirow{2}{*}{$\begin{array}{l}\text { Interval } \\
\text { in Days }\end{array}$} & \multicolumn{2}{|c|}{ Paralysis } & \multirow{2}{*}{$\begin{array}{l}\text { Type of Virus } \\
\text { Isolated }\end{array}$} \\
\hline & & & Bulbar & Spinal & \\
\hline $\begin{array}{c}\mathbf{M} \\
\mathbf{M} \\
\mathbf{M} \\
\mathbf{F} \\
\mathbf{M} \\
\mathbf{F} \\
\mathbf{M} \\
\mathbf{M} \\
\mathbf{M} \\
\mathbf{F}\end{array}$ & $\begin{array}{l}3 \\
1 \\
2 \\
3 \\
4 \\
4 \\
3 \\
5 \\
3 \\
3\end{array}$ & $\begin{array}{r}1 \\
3 \\
14 \\
7 \\
4 \\
17 \\
1 \\
1 \\
8 \\
20\end{array}$ & $\begin{array}{l} \pm \\
= \\
= \\
= \\
= \\
= \\
= \\
=\end{array}$ & $\begin{array}{l}- \\
+ \\
+ \\
+ \\
+ \\
= \\
= \\
= \\
-\end{array}$ & 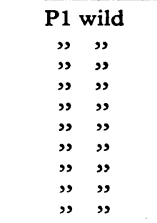 \\
\hline
\end{tabular}

in Table VI, and it will be seen that in seven of the patients the illness occurred within nine days of receiving the vaccine. In the other three patients the intervals were 14,17 , and 20 days, and the strains appeared to be of the wild type. In the case of the child whose stool contained two viruses the interval between administration of the vaccine and the illness was four weeks. He had a transient weakness of the left arm and his neutralizing antibodies to type 1 poliovirus were high in both specimens.

Regarding the second complication, complement-fixation tests using mumps $S$ and $V$ antigens were carried out with the sera from the patients, but in no instance was a significant rise in titre obtained.

There were, however, four patients with aseptic meningitis from whom poliovirus was isolated but who were not regarded as suffering from clinical poliomyelitis ; the mumps serological findings in these patients are set out in Table VII. It will be seen that two of the children had received a single dose of live vaccine four weeks prior to the onset of illness. The boy aged 4 years had parotitis as well as aseptic meningitis.

TABLE VII.-Clinical Details, Vaccination State, and Production of Mumps Virus Antibodies in Four Patients with Aseptic Meningits from whom Poliovirus was Isolated but Who were Thought to be Suffering from Mumps

\begin{tabular}{|c|c|c|c|c|c|c|}
\hline \multirow{2}{*}{ Sex } & \multirow{2}{*}{$\begin{array}{l}\text { Age } \\
\text { in } \\
\text { Years }\end{array}$} & \multicolumn{2}{|c|}{ Doses of Vaccine } & \multirow{2}{*}{$\begin{array}{c}\text { Type of } \\
\text { Poliovirus } \\
\text { Isolated }\end{array}$} & \multicolumn{2}{|c|}{ Mumps Antibodies } \\
\hline & & Inactivated & Live & & S & $\mathbf{v}$ \\
\hline $\begin{array}{c}M \\
M \\
F\end{array}$ & $\begin{array}{l}3 \\
5 \\
4\end{array}$ & $\begin{array}{l}3 \\
3 \\
0\end{array}$ & $\begin{array}{l}0 \\
0 \\
1 \\
1\end{array}$ & $\begin{array}{l}1 \\
2 \\
3\end{array}$ & $\begin{array}{r}8 / 16 \\
8 / 16 \\
16 / 16\end{array}$ & $\begin{array}{l}<8 / 256 \\
<8 / 556 \\
32 / 256\end{array}$ \\
\hline $\mathbf{M}$ & 4 & 0 & $\begin{array}{c}(4 \text { Wks. } \\
1 \\
(4 \text { wks.) }\end{array}$ & 3 & $16 /<8$ & $64 / 256$ \\
\hline
\end{tabular}

Mumps antibody numerator $=$ Acute phase serum reciprocal titre.

Mumps antibody denominator $=$ Convalescent phase serum reciprocal titre.

\section{Previous Outbreaks of Poliomyelitis in Dundee}

In Dundee, an industrial city with a population of 183,000 , outbreaks have occurred from time to time, particularly since 1947 (Table VIII). The ages of the patients affected in the three main outbreaks are shown in Table IX, and at first sight the high attack rate in young children in 1962 is some-

\begin{tabular}{c|c|c|c}
\multicolumn{2}{c}{ TABLE VIII.-Yearly Incidence of Confirmed Cases of Poliomyelitis } \\
\hline Year & $\begin{array}{c}\text { No. of } \\
\text { Cases }\end{array}$ & Year & $\begin{array}{c}\text { No. of } \\
\text { Cases }\end{array}$ \\
\hline 1947 & 43 & 1955 & 13 \\
1948 & 9 & 1956 & 3 \\
1949 & 7 & 1957 & 5 \\
1950 & 94 & 1958 & 20 \\
1951 & 16 & 1959 & 1 \\
1952 & 5 & 1960 & 3 \\
1953 & 6 & 1962 & 40 \\
1954 & 11 & & 3
\end{tabular}

TABle IX.-Age Distribution in Three Dundee Outbreaks

\begin{tabular}{|c|c|c|c|}
\hline Age in Years & $\begin{array}{c}1947 \\
\text { (43 cases) }\end{array}$ & $\begin{array}{c}1950 \\
\text { (94 cases) }\end{array}$ & $\begin{array}{c}1962 \\
(40 \text { cases })\end{array}$ \\
\hline $\begin{array}{l}\text { Under } 2 \\
2-5 \\
6-15 \\
\text { Over } 16\end{array}$ & $\begin{array}{c}19 \% \\
32 \% \\
26 \% \\
23 \%\end{array}$ & $\begin{array}{c}35 \% \\
39 \% \\
14 \% \\
12 \%\end{array}$ & $\begin{array}{c}20 \% \\
67.5 \% \\
7.5 \% \\
5 \% \\
5 \%\end{array}$ \\
\hline
\end{tabular}

what surprising. Two possible contributory factors, however, have to be considered: firstly, the amount and age distribution of naturally acquired immunity in the population, and, secondly, the presence of artificially acquired immunity following the use of inactivated poliovaccine prior to the outbreak of 1962 .

In 1956 a small survey was carried out in King's Cross Hospital in an attempt to assess the presence of natural antibody prior to the introduction of inactivated vaccine. Neutralization tests against the three types of poliovirus (MacLeod et al. 
1958) were carried out on a group of 94 patients in social grades III, IV, and V, aged between 1 and 12 years, suffering from a variety of diseases, but excluding any child suffering from illness involving the central nervous system. A further group of 61 healthy children in social grades I and II were also examined. The results of this investigation (Table $\mathrm{X}$ ) suggested that poliovirus had been, and still was, widespread in Dundee up to 1956, and that for social grades III, IV, and V the figure of $90 \%$ infected was being reached by the ages of 4 and 5 years. Where social standards were higher (social grades I and II) the peak of infection was delayed until somewhere between 8 and 11 years. In the 1962 outbreak the bulk of the affected patients were in certain new housing schemes and from social groups roughly equivalent to social grades III, IV, and V; it would appear, therefore, that if the state of naturally acquired immunity in the city in 1962 was similar to that suggested in Table $\mathrm{X}$ the attack on the younger agegroups is understandable. A further factor may have been the pattern of the immunization campaign with inactivated vaccine, where the main effort was concentrated on children of school age (see below).

When one considers the monthly incidence of poliomyelitis in Dundee a striking difference is observed between the 1962 outbreak and all previous outbreaks (Table XI). The latter

TABLE X.-Naturally Occurring Neutralizing Antibodies to Poliovirus in

\begin{tabular}{c|c|c|c|c|c|c|c} 
Two Groups of Children in Dundee in 1956 \\
\hline $\begin{array}{c}\text { Social } \\
\text { Grades }\end{array}$ & 1 & 2,3 & 4,5 & 6,7 & 8,9 & 10,11 & 12 \\
\hline UII, IV, V & $\begin{array}{c}13 / 20 \\
0 / 0\end{array}$ & $\begin{array}{c}23 / 30 \\
0 / 4\end{array}$ & $\begin{array}{r}19 / 21 \\
3 / 13\end{array}$ & $\begin{array}{c}9 / 10 \\
10 / 19\end{array}$ & $\begin{array}{c}7 / 8 \\
11 / 14\end{array}$ & $\begin{array}{c}4 / 4 \\
8 / 9\end{array}$ & $\begin{array}{c}1 / 1 \\
2 / 2\end{array}$ \\
\hline
\end{tabular}

Numerator $=$ Number of children possessing antibody to one or more types of Numerator

Denominator $=$ Number of children whose sera were tested.

TABLE XI.-Monthly Notification of Cases of Poliomyelitis in Outbreaks in Dundee for Period 1947-1962

\begin{tabular}{c|c|c|c|c|c|c|c|c|c|c|c|c}
\hline & Jan. & Feb. & Mar. & Apr. & May & June & July & Aug. & Sep. & Oct. & Nov. & Dec. \\
\hline 1947 & 0 & 0 & 0 & 1 & 0 & 0 & 0 & 7 & 24 & 9 & 2 & $\theta$ \\
1950 & 0 & 0 & 0 & 0 & 1 & 5 & 16 & 32 & 28 & 11 & 1 & 0 \\
1951 & 0 & 0 & 1 & 1 & 0 & 0 & 0 & 1 & 2 & 5 & 1 & 5 \\
1954 & 1 & 1 & 1 & 1 & 0 & 1 & 2 & 2 & 2 & 0 & 0 & 0 \\
1955 & 0 & 0 & 0 & 0 & 0 & 1 & 2 & 0 & 1 & 2 & 4 & 3 \\
1958 & 1 & 1 & 2 & 0 & 1 & 3 & 6 & 4 & 1 & 1 & 0 & 0 \\
1962 & 0 & 0 & 0 & 0 & 3 & 32 & 5 & 0 & 0 & 0 & 0 & 0
\end{tabular}

were more protracted, the main incidence occurring in the late summer and autumn months. By contrast the 1962 outbreak occurred in the early summer months and was of short duration, being over within a period of seven weeks, during the last three of which oral vaccine had been widely administered.

\section{Previous Vaccination History in Dundee}

Inactivated Vaccine.-This vaccine was introduced on a very limited scale towards the end of 1956, when a few selected children in age-group 1-10 years were given two injections. In 1958 more vaccine became available, and this was used for children up to the age of 15 years, expectant mothers, doctors, nurses, and certain others at special risk. In 1959 an intensive campaign became possible and vaccine was offered to all agegroups up to 25 years; records show that 55,000 persons received two or more doses of vaccine about this time. In

Table XII.-Proportion of Population of Dundee Having Received

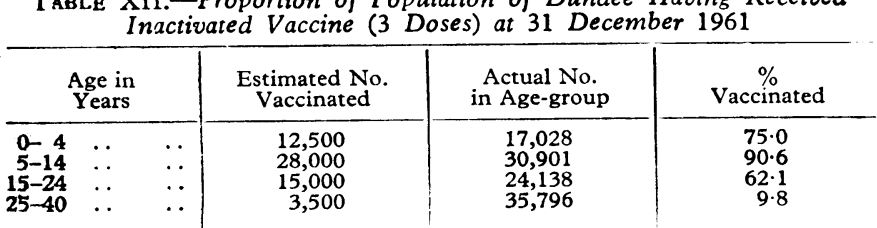

1960-1 the campaign was continued, but acceptance rates were not so high. The situation pertaining at the end of 1961 is shown in Table XII.

Live Attenuated Vaccine.-In the spring of 1962 oral trivalent vaccine became available and was used in child welfare clinics for infants over the age of six months, and also for "booster" purposes in children who had joined school in February 1962. At the clinics 220 infants were vaccinated, while of 1,900 children of school age eligible 1,744 were vaccinated.

\section{Management of 1962 Outbreak}

From the start routine measures were adopted for the control of household contacts and trivalent oral vaccine was offered to all of these. On 11 June it was decided to offer this vaccine more widely, concentrating on children and, to a less extent, adults domiciled in the affected north-eastern part of the city. Increased numbers of vaccination sessions were arranged at the area health clinic and nearly 3,000 persons in this main affected area (population 12,000 approximately) received a dose of vaccine in the ensuing week. On 14 June, however, the death of an adult male patient from the disease received considerable publicity in the local press, and this precipitated an immediate public reaction not only in the affected housing area but also widely throughout the city. Emergency arrangements were consequently made for all sections of the town, and trivalent oral vaccine, which was readily available, was used. By 16 June about 5,000 doses had been given; by 23 June the total reached 18,500 ; by 30 June the figure had risen to just over 50,000 ; and by 7 July almost half the total population of the city had received a single dose of the oral vaccine. No more cases occurred after 4 July, but the vaccination campaign continued and eventually over 100,000 persons, or practically two-thirds of the population, had been given the vaccine. The Chart shows the number of persons who received one dose of vaccine related to the weekly incidence of poliomyelitis.

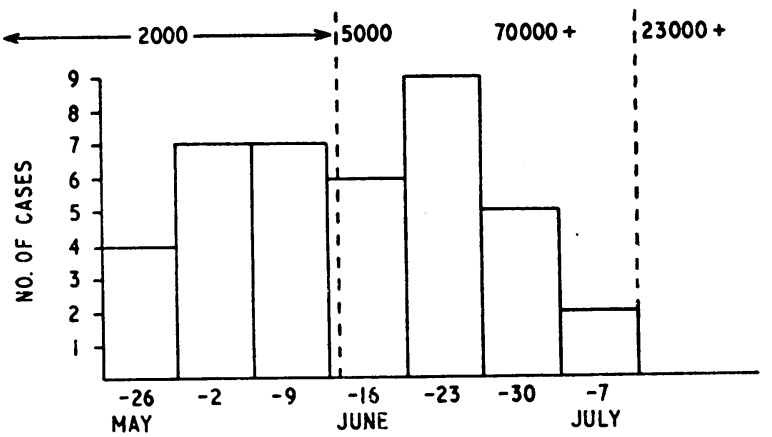

Number of persons receiving a single dose of trivalent attenuated live vaccine related to the weekly incidence of cases of poliomyelitis.

It has been shown that the use of poliovirus type 2 live vaccine was very effective in preventing the extension of epidemics of poliomyelitis in Singapore in 1958-9 (Hale et al., 1959) and in Hull in 1961 (Ministry of Health, 1963), and we think that the extensive use of trivalent live vaccine brought the epidemic in Dundee to an abrupt end. This abrupt ending was in contrast to the position in Glasgow in the same year, where, without an intensive vaccination campaign, cases of poliomyelitis occurred until the end of the year (Green and Bell, 1963).

The decision to use trivalent vaccine instead of a monovalent heterotypic vaccine was made because the trivalent vaccine had been used already in the city and it was felt that the continuation of the same vaccine was the best policy.

We can only speculate on what would have been the course of events in Dundee if . the intensive campaign had been restricted to the main affected area of the city, but it should 
be pointed out that the disease had already shown signs of spreading outside this area, and there were many parts of the city which were as vulnerable, if not more so, than the one that was affected. There will obviously be considerable interest in the trend of poliomyelitis in Dundee over the next few years. The population had probably a high degree of natural protection, and this had already been reinforced by the fairly extensive use of inactivated vaccine before being boosted still further by the widespread use of trivalent attenuated live vaccine in the 1962 outbreak.

\section{Summary}

An outbreak of poliomyelitis involving 40 patients occurred during the early summer of 1962 in the city of Dundee, particularly in certain new housing areas in the north-eastern part of the city. The causal virus was poliovirus type 1 . An interesting feature was that the main attack was on children below the age of 6 years ; it is suggested that this was perhaps not surprising in view of the probable age distribution of both natural and acquired antibody in the population.

Trivalent attenuated vaccine, given orally, was used on a large scale in an effort to cut short the outbreak; within three weeks of the start of an intensive campaign, and when approximately half of the population had received a single dose of vaccine, the outbreak came to an- abrupt end. An intratypic serodifferentiation method was used to distinguish between wild and vaccine type poliovirus isolated from patients who had received live vaccine.

It is a pleasure to acknowledge our indebtedness to our respective staffs in the City of Dundee Public Health Department, in King's Cross Hospital, and in the virological section of the bacteriology department, Queen's College, Dundee. We are particularly grateful to Dr. N. R. Grist and Dr. Eleanor Bell, Virus Laboratory, Ruchill Hospital, Glasgow, for the intratypic serodifferentiation of some of the strains of virus, and to Mr. J. Hutchison, orthopaedic surgeon, for his independent assessment of severity in the paralytic cases.

\section{REFERENCES}

Duncan, I. B. R., and Bell, Eleanor J. (1961). Brit. med. Y., 2, 863. Goffe, A. P., and Bell, Eleanor J. (1963). 9th European Symposinm on Poliomyelitis and Allied Diseases, September 1963. Stockbolm Green, D. M., and Bell, Eleanor J. (1963). Ibid.

Hale, J. H., Doraisingham, M., Kanagaratnam, K., Leang, K. W., and Monteiro, E S. (1959). Brit. med. F., 1, 1541 .

MacLeod, R. C., MacGregor, Lilias, G., Larminie, Helen E., and Grish N. R. (1958). Scot. med. 7., 3, 76.

Mair, Hélène, J., and Tobin, J. O'H. (1960). Mth. Bull. Mintst. Hlth Lab. Serv., 19, 49.

Ministry of Health (1963). Reports on Public Health and Medical Subjects No. 107. H.M.S.O., London.

Shand, F. L. (1961). 7. med. Lab. Technol., 18, 75.

Wallis, C., and Melnick, J. L. (1962). Virology, 16, 122.

\title{
Role of Phosphate in Treatment of Renal Tubular (Hypophosphataemic) Rickets and Osteomalacias
}

\author{
G. ALAN ROSE,* D.M., F.R.I.C.
}

Brit. med. F., 1964, 2, 857-861

Rickets and osteomalacia continue to occur in this country. Vitamin-D deficiency, once thought to be an extreme rarity here, has now recurred (Dunnigan et al., 1962 ; Benson et al., 1963 ; Arneil and Crosbie, 1963). Chronic renal failure and steatorrhoea both continue to cause syndromes in which the affected persons behave as though they were vitamin-Ddeficient, even though they are not. Such individuals have therefore been termed vitamin-D-resistant. The vitamin-Dresistant state described by Albright et al. (1937) is probably still, however, the most common cause of rickets and osteomalacia in this country to-day (Stewart et al., 1964). In this disease many observers have found a low renal tubular reabsorption of phosphate, and there is clearly a renal tubular leak for inorganic phosphate. It is stressed, however, that the term " renal tubular leak" implies nothing about the mechanism by which this leak occurs. Because of the leak, the plasma phosphate is always low and the disease has been named hypophosphataemic rickets by some (Winters et al., 1958), and phosphate diabetes by others (Fanconi and Girardet, 1952). An alternative system of nomenclature, and the one to be used here henceforth, was devised by Dent (1952). Using this system, six types of renal tubular osteomalacia are recognized. Type 1 cases show only the one renal tubular abnormality-that is, the phosphate leak; type 2 cases show two tubular abnormalities-namely, renal glycosuria in addition to the phosphate

\footnotetext{
- From the Metabolic Unit, Department of Medicine, Leeds General Infirmary.
}

leak; while types 3-6 show more tubular abnormalities, sucb as renal tubular acidosis.

Many recent papers have shown that type 1 renal tubular rickets and osteomalacia can be cured by large doses of vitamin D. Dent and Harris (1956), however, pointed out that the resistance to vitamin $D$ affects only the therapeutic effect of the vitamin and not the toxic effects. Therefore the therapeutic range may become very small and the treatment correspondingly hazardous, with the risk of hypercalcaemia always present. Not only is this treatment hazardous, but it is hard to control, the dose required to cure the rickets being very much larger than the dose required to maintain the patient healed. Sometimes it has been found impossible to heal the osteomalacia with vitamin $D$ alone (Frame and Smith, 1958). At other times healing may occur, but it may take a remarkably long time for the treatment to be effective in relieving symptoms, as illustrated by Case 1 below. For these various reasons other possible therapies have been under investigation in this unit, and the effects of phosphate therapy in two further patients are now reported.

\section{Methods}

All investigations were carried out in an air-conditioned metabolic unit. The methods used in the balance studies were as previously described (Rose, 1964a) except that the balance study in Case 1 was carried out without the use of chromium sesquioxide marker, and calcium was determined by oxalate 